\title{
Rettighetsvurdering og kvalitet på henvisninger - grad av samsvar mellom fire smertesentre
}

ORIGINALARTIKKEL

MONA STEDENFELDT

E-post: mona.stedenfeldt@stolav.no

Regionalt senter for helsetjenesteutvikling

St. Olavs hospital

og

Institutt for sirkulasjon og bildediagnostikk

NTNU

Hun har bidratt med idé, utforming/design, datainnsamling, analyse av data, tolking av data, litteratursøk, utarbeiding/revisjon av selve manuset, godkjenning av innsendte manusversjon. Mona Stedenfeldt er ph.d., forsker og førsteamanuensis.

Forfatteren har fylt ut ICMJE-skjemaet og oppgir følgende interessekonflikt: Prosjektet er en del av et evalueringsprosjekt som Helse- og omsorgsdepartementet finansierer.

\section{GUNNVALD KVARSTEIN}

Institutt for klinisk medisin

Universitetet i Troms $\emptyset$ - Norges arktiske universitet

og

Smerteavdelingen

Universitetssykehuset Nord-Norge, Troms

og

Avdeling for smertebehandling

Oslo universitetssykehus

Hun har bidratt med idé, utforming/design, utarbeiding/revisjon av selve manuset, godkjenning av innsendte manusversjon.

Gunnvald Kvarstein er spesialist i anestesiologi, professor og overlege.

Forfatteren har fylt ut ICMJE-skjemaet og oppgir ingen interessekonflikter.

\section{BORRIK SCHJØDT}

Seksjon for smertebehandling og palliasjon

Haukeland universitetssjukehus

Han har bidratt med datainnsamling, utarbeiding/revisjon av selve manuset, godkjenning av innsendte manusversjon.

Borrik Schjødt er psykologspesialist i samfunnspsykologi og i voksenpsykologi og seniorpsykologspesialist.

Forfatteren har fylt ut ICMJE-skjemaet og oppgir ingen interessekonflikter.

\section{ASLAK JOHANSEN}

Smerteavdelingen

Universitetssykehuset Nord-Norge, Troms $\emptyset$

Han har bidratt med datainnsamling, utarbeiding/revisjon av selve manuset, godkjenning av 
innsendte manusversjon.

Aslak Johansen er ph.d., spesialist i anestesiologi og avdelingsoverlege.

Forfatteren har fylt ut ICMJE-skjemaet og oppgir ingen interessekonflikter.

\section{ANNE GINA SCHIE BERNTSEN}

Avdeling for smertebehandling

Oslo universitetssykehus

Hun har bidratt med datainnsamling, utarbeiding/revisjon av selve manuset, godkjenning av innsendte manusversjon.

Anne Gina Schie Berntsen er spesialist i anestesiologi, overlege og seksjonsleder.

Forfatteren har fylt ut ICMJE-skjemaet og oppgir ingen interessekonflikter.

\section{ASTRID BRAUTASET}

Avdeling for smerte og sammensatte lidelser - Smertesenteret

St. Olavs hospital

Hun har bidratt med datainnsamling, utarbeiding/revisjon av selve manuset, godkjenning av innsendte manusversjon.

Astrid Brautaset er spesialist i fysikalsk medisin og rehabilitering og overlege.

Forfatteren har fylt ut ICMJE-skjemaet og oppgir ingen interessekonflikter.

\section{VIDAR HALSTEINLI}

Regionalt senter for helsetjenesteutvikling

St. Olavs hospital

og

Institutt for samfunnsmedisin og sykepleie

NTNU

Han har bidratt med idé, utforming/design, tolking av data, litteratursøk, utarbeiding/revisjon av selve manuset, godkjenning av innsendte manusversjon.

Vidar Halsteinli er ph.d., helseøkonom, forsker og førsteamanuensis.

Forfatteren har fylt ut ICMJE-skjemaet og oppgir følgende interessekonflikt: Prosjektet er en del av et evalueringsprosjekt som Helse- og omsorgsdepartementet finansierer.

\section{BAKGRUNN}

Langvarige smerter er et utbredt helseproblem. De fire regionale tverrfaglige smertesentrene i Norge mottar årlig ca. 5 ooo henvisninger fra fastleger og spesialisthelsetjenesten. Et likeverdig tilbud tilsier at henvisninger bør vurderes likt. Formålet med studien var å evaluere grad av samsvar mellom smertesentrenes inntaksteam i vurdering av kvalitet på mottatte henvisninger og i vurdering av pasientenes rett til nødvending helsehjelp.

\section{MATERIALE OG METODE}

Hvert inntaksteam vurderte 40 henvisninger. De foretok «primærvurdering» av 10 ordinært mottatte henvisninger og «sekundærvurdering» av zo henvisninger sendt ordinært til de $\emptyset$ vrige sentrene. Hver henvisning ble kvalitets- og rettighetsvurdert ved hvert senter. Andel enighet og intraklassekorrelasjonskoeffisient (ICC) ble brukt for å vurdere samsvar mellom inntaksteamene.

\section{RESULTATER}

Kvaliteten på henvisningene ble vurdert som «ikke god» i 45 \% av primærvurderingene og i $43 \%$ av sekundærvurderingene. Samsvar mellom inntaksteamene varierte fra lavt (ICC = o,19) til moderat (ICC = o,74). Primærvurderingene og sekundærvurderingene ga begge $63 \%$ av pasientene «rett til helsehjelp». Andel enighet var samlet sett $69 \%$, dvs. lavere enn det som regnes som «akseptabel enighet» $(75 \%)$. 
Studien viser at det er behov for strukturerte henvisninger, og at inntaksteamene i større grad bør samstemmes i vurderingene sine for å sikre et likeverdig tilbud på tvers av helseregionene.

Langvarige smerter er et utbredt helseproblem $(1,2)$ der ulike faktorer kan påvirke smerteopplevelse og funksjonsevne. Pasientene følges opp av fastlege, men kan ha behov for oppfølging fra helseforetakenes tverrfaglige smerteklinikker eller ved tverrfaglige smertesentre (3).

Veien inn til det spesialiserte smertetilbudet krever henvisning fra fastlege eller spesialisthelsetjenesten. Henvisningene vurderes innen ti dager, fortrinnsvis av tverrfaglige inntaksteam $(3,4)$. Rett til helsehjelp tildeles dersom pasienten «kan ha forventet nytte av helsehjelpen og de forventede kostnadene står i et rimelig forhold til tiltakets effekt» (5).

I pasient og brukerrettighetsloven § 2-2 presiseres det at rettighetstildelingen skal skje på grunnlag av henvisningen (6), og i den nasjonale faglige veilederen for organisering og drift av tverrfaglige smertesentre (3) understrekes det at henvisningen må gi en «tydelig beskrivelse av pasientens problem» og inneholde "opplysninger som karakteriserer pasienten i en biopsykososial forståelse». En mangelfull henvisning kan gjøre det vanskelig å vurdere om pasienten skal gis rett til helsehjelp eller ikke. I veilederen påpekes det derfor at «en fyldig og poengtert henvisning er den beste garanti for at pasienten skal få korrekt prioritet» (3).

Flere studier har vist at henvisninger til spesialisthelsetjenesten er av varierende kvalitet (7-12). Lønning og medarbeidere (2009) fant at en tredjedel av 198 innkommende henvisninger til medisinsk poliklinikk ved Sykehuset Buskerud var mangelfulle (7). I en evaluering av 256 henvisninger til tverrfaglig ryggpoliklinikk ved St. Olavs hospital fant Gulati og medarbeidere (2012) at kun 2,1\% inneholdt informasjon som dekket antatt viktige kategorier (8).

I tillegg til henvisningskvalitet er det avgjørende at kriteriene for «rett til helsehjelp» tolkes og praktiseres likt. Det finnes eksempler på at dette ikke er tilfelle. I en studie av 14 distriktspsykiatriske sentre ble det funnet liten grad av enighet i rettighetsvurderingene (13).

I 2015 og 2016 bevilget Stortinget midler til et pilotprosjekt for utvikling og drift av tverrfaglige tilbud for pasienter med langvarige smerte- og utmattelsestilstander. Et hovedmål var «å etablere et godt og nasjonalt samordnet tilbud til denne pasientgruppen» (14-16). Regionalt senter for helsetjenesteutvikling ved St. Olavs hospital evaluerer pilotprosjektet. Her rapporterer vi funn fra første studie i evalueringen. Formålet med studien var å undersøke 1) i hvilken grad inntaksteamene ved fire smertesentre har sammenfallende vurderinger av kvaliteten på mottatte pasienthenvisninger, og 2) om teamene har sammenfallende konklusjon om pasientenes rett til nødvending helsehjelp.

\section{Materiale og metode}

Studien er basert på 40 henvisninger vurdert av inntaksteamene ved fire smertesentre: Seksjon for smertebehandling og palliasjon ved Haukeland universitetssjukehus, Smerteavdelingen ved Universitetssykehuset Nord-Norge, Avdeling for smertebehandling ved Oslo universitetssykehus og Avdeling for smerte og sammensatte lidelser Smertesenteret ved St. Olavs hospital. Inntaksteamene er tverrfaglige med lege(r), psykolog(er) og fysioterapeut(er). I uke 38 og 39 i 2017 inkluderte hvert inntaksteam fortløpende ti ordinære henvisninger og rettighetsvurderte dem på vanlig måte. Disse vurderingene omtales heretter som «primærvurderinger». Henvisningene ble anonymisert og sendt til prosjektleder. Sentrene mottok deretter kopi av henvisningene fra hvert av de 
$\emptyset$ vrige tre sentrene. Alle fire inntaksteam foretok dermed ytterligere zo vurderinger, her omtalt som «sekundærvurderinger».

Ut fra anbefalinger i veilederen «Organisering og drift av tverrfaglige smerteklinikker» (3) om hva en god henvisning bør inneholde, utarbeidet representanter for de fire inntaksteamene og prosjektleder et kartleggingsskjema for vurdering av henvisningene (se appendiks). Inntaksteamene ble bedt om å 1) angi hvilke opplysninger som ble tillagt vekt i vurderingen av henvisningen (med alternativene «av stor betydning», «noe», «ingen» eller «ikke tilstrekkelig beskrevet»), 2) vurdere henvisningens kvalitet («ikke god», "god» eller «meget god») og 3) gi prioritet («rett til helsehjelp», «ikke rett til helsehjelp» eller «behov for ytterligere informasjon»).

I primærvurderingen kunne supplerende informasjon fra pasientens journal benyttes $\mathrm{i}$ rettighetsvurderingen, noe som også ble registrert i kartleggingsskjemaet.

Etter sekundærvurdering ble henvisningskopiene og kartleggingsskjemaene, som begge var merket med unike nummer for å sikre korrekt kobling, returnert til prosjektleder. Alle 40 henvisningene ble vurdert fire ganger - én primærvurdering og tre sekundærvurderinger altså foretok teamene 160 vurderinger til sammen.

Regional komité for medisinsk og helsefaglig forskningsetikk (REK) vurderte studien som en kvalitetssikringsstudie og utenfor deres ansvarsområde. Ut fra Norsk senter for forskningsdata (NSD) sin meldeplikt-test (17) var prosjektet ikke meldepliktig siden datamaterialet var anonymisert.

To statistiske metoder ble brukt for å vurdere samsvar mellom inntaksteamene (interraterreliabilitet): andel enighet ("percent agreement») og intraklassekorrelasjonskoeffisient (ICC). Andel enighet (18) ble benyttet når det ikke var tilstrekkelig variasjon i vurderingene, noe som oppstår når man har få svarkategorier (19). Andel enighet ble vurdert til å være tilstrekkelig - eller akseptabel - om enigheten var mellom 75 og $90 \%$ (20). ICC ble benyttet for å evaluere samsvar mellom primær- og sekundærvurdering av kvalitet, og da med følgende formel: ICC (absolutt enighet, $\mathrm{k}$ vurderingsteam $)=$ variasjon $\mathrm{i}$ kvalitetsvurdering for hver henvisning $/($ variasjon $\mathrm{i}$ kvalitetsvurdering for hver henvisning + (variasjon i repetisjon + målefeil) / k) (19). Siden evalueringsteamene ikke var tilfeldig plukket ut, ble det benyttet en tosidig blandet effektmodell med henvisningens kvalitet som avhengig variabel. Vi brukte gjennomsnittet av vurderingene fra inntaksteamene og absolutt enighet (dvs. alle fire inntaksteam vurderte likt) som definisjon (19). Det ble utført fire ICC-analyser, en for hvert primærvurderende senter opp mot de tre sekundærvurderende sentrene. Statistiske analyser ble utført med IBM SPSS Statistics versjon 23 (IBM Corp., Armonk, NY).

Det er ingen klar konsensus om hvilken ICC-verdi som representerer akseptabel enighet. I tråd med tidligere anbefalinger (13, 21) valgte vi å benytte følgende retningsgivende verdier: ICC $<0,20=$ liten enighet; $0,21-0,40=$ svak enighet; $0,41-0,60=$ moderat enighet; $0,61-0,80=$ god enighet; $>0,80=$ meget god enighet.

\section{Resultater}

\section{OPPLYSNINGER I HENVISNING OG BETYDNING FOR VURDERING}

Av 16 informasjonskategorier ble 7 angitt som «ikke tilstrekkelig beskrevet» i over halvparten av de 160 vurderingene. I mer enn $70 \%$ av vurderingene gjaldt dette kategoriene «angitt motivasjon til tilbud» ( $85 \%$ ), «rus-/avhengighetsproblematikk» (78\%) og «søvnplager» ( $76 \%$ ) (tabell 1). For disse tre kategoriene var andel enighet mellom inntaksteamene henholdsvis $85 \%, 83 \%$ og $84 \%$.

\section{Tabell 1}




\begin{tabular}{|c|c|c|c|c|}
\hline Informasjon i henvisningene $(\mathrm{N}=160)$ & $\begin{array}{r}\text { Av stor/noe } \\
\text { betydning }\end{array}$ & Ingen & $\begin{array}{r}\text { Ikke } \\
\text { tilstrekkelig } \\
\text { beskrevet }\end{array}$ & $\begin{array}{r}\text { Andel } \\
\text { enighet } \\
(\%)\end{array}$ \\
\hline Angitt motivasjon til tilbud ${ }^{1}$ & $18(11)$ & $5(3)$ & $134(85)$ & 85 \\
\hline Rus-/avhengighetsproblematikk & $25(16)$ & $11(7)$ & $124(78)$ & 83 \\
\hline Søvnplager & $33(21)$ & $5(3)$ & $122(76)$ & 84 \\
\hline Tidligere behandling på smerteklinikk ${ }^{2}$ & $38(24)$ & $11(7)$ & $107(67)$ & 70 \\
\hline Smertekarakter ${ }^{3}$ & $40(25)$ & $\begin{array}{r}19 \\
(12)\end{array}$ & $100(63)$ & 71 \\
\hline $\begin{array}{l}\text { Depressive plager / angst / } \\
\text { katastrofetanker }\end{array}$ & $54(35)$ & $8(5)$ & $98(61)$ & 76 \\
\hline Smerteintensitet & $61(39)$ & $13(8)$ & $86(54)$ & 65 \\
\hline Aktivitetsnivå / fysiske begrensninger & $77(48)$ & $5(3)$ & $78(49)$ & 73 \\
\hline Vurdert som ferdig utredet & $117(73)$ & $9(6)$ & $34(21)$ & 71 \\
\hline Lokalisasjon av smerte & $115(72)$ & $\begin{array}{r}26 \\
(16) \\
\end{array}$ & $19(12)$ & 61 \\
\hline $\begin{array}{l}\text { Tidligere behandling utenom } \\
\text { smerteklinikk }\end{array}$ & $101(64)$ & $12(8)$ & $47(29)$ & 52 \\
\hline Varighet av symptomer ${ }^{3}$ & $93(58)$ & $\begin{array}{r}23 \\
(14)\end{array}$ & $43(27)$ & 60 \\
\hline $\begin{array}{l}\text { Funn fra klinisk undersøkelse / } \\
\text { supplerende undersøkelser } \\
\text { (bildeundersøkelse, EMG, nevrografi, } \\
\text { lab etc.) }\end{array}$ & $85(54)$ & $6(4)$ & $69(43)$ & 68 \\
\hline Komorbiditet & $83(52)$ & $21(13)$ & $56(35)$ & 63 \\
\hline $\begin{array}{l}\text { Sosial status (familiesituasjon, venner, } \\
\text { sosial funksjon) }\end{array}$ & $68(42)$ & $\begin{array}{r}30 \\
(19)\end{array}$ & $62(39)$ & 64 \\
\hline Arbeid & $62(39)$ & $\begin{array}{r}58 \\
(36) \\
\end{array}$ & $40(25)$ & 70 \\
\hline
\end{tabular}

${ }^{1} \mathrm{n}=157$

${ }^{2} \mathrm{n}=156$

${ }^{3} n=159$

\section{HENVISNINGENES KVALITET}

Av de primærvurderte henvisningene ble $45 \%$ vurdert som «ikke god», $40 \%$ som «god» og $15 \%$ som «meget god». Ved sekundærvurderingene var samlet fordeling henholdsvis $43 \%$, $45 \%$ og $12 \%$. Tabell 2 viser hvordan primær- og sekundærvurderingene av henvisningens kvalitet fordelte seg mellom «ikke god», "god» og «meget god» for hvert senter, og grad av samsvar (ICC) mellom primær- og sekundærvurderingen. Samsvar mellom primærvurderingen og de respektive sekundærvurderingene var god for henvisninger som ble primærvurdert ved Haukeland universitetssjukehus, moderat for primærvurderinger ved Oslo universitetssykehus og Universitetssykehuset Nord-Norge, og liten for primærvurderinger ved St. Olavs hospital. Sistnevnte senter skilte seg ut ved at kvaliteten på alle ti henvisninger ble primærvurdert som «ikke god», mens de tre andre sentrene vurderte kvaliteten som «god» for et flertall av de samme henvisningene.

\section{Tabell 2}

Enighet i vurdering av kvalitet mellom primærvurderinger fra hvert senter og korresponderende sekundærvurderinger. Antall henvisninger per svaralternativ. HUS = Haukeland universitetssjukehus, OUS = Oslo universitetssykehus, STO = St. Olavs hospital, 
UNN = Universitetssykehuset Nord-Norge

\begin{tabular}{|c|c|c|c|c|}
\hline & \multicolumn{4}{|c|}{ Henvisningens kvalitet Absolutt enighet } \\
\hline & \multicolumn{3}{|c|}{ Ikke god God Meget god } & \multirow[t]{2}{*}{$\mathrm{ICC}^{1}$} \\
\hline Primærvurdering (HUS) & 3 & 6 & 1 & \\
\hline Sekundærvurdering (UNN) & 2 & 6 & 2 & \\
\hline Sekundærvurdering (OUS) & 3 & 6 & 1 & \\
\hline \multirow[t]{2}{*}{ Sekundærvurdering (STO) } & 7 & 3 & 0 & \\
\hline & 15 & 21 & 4 & $0,74(0,36-0,92)$ \\
\hline Primærvurdering (UNN) & 3 & 3 & 4 & \\
\hline Sekundærvurdering (STO) & 8 & 2 & 0 & \\
\hline Sekundærvurdering (OUS) & 4 & 2 & 4 & \\
\hline \multirow[t]{2}{*}{ Sekundærvurdering (HUS) } & 6 & 4 & 0 & \\
\hline & 21 & 11 & 8 & $0,51(-0,05-0,85)$ \\
\hline Primærvurdering (OUS) & 2 & 7 & 1 & \\
\hline Sekundærvurdering (STO) & 8 & 2 & 0 & \\
\hline Sekundærvurdering (HUS) & 5 & 4 & 1 & \\
\hline \multirow[t]{2}{*}{ Sekundærvurdering (UNN) } & 3 & 5 & 2 & \\
\hline & 18 & 18 & 4 & $0,57(0,03-0,87)$ \\
\hline Primærvurdering (STO) & 10 & 0 & 0 & \\
\hline Sekundærvurdering (OUS) & 1 & 6 & 3 & \\
\hline Sekundærvurdering (HUS) & 2 & 8 & 0 & \\
\hline \multirow[t]{2}{*}{ Sekundærvurdering (UNN) } & 3 & 6 & 1 & \\
\hline & 16 & 20 & 4 & $0,19(-0,27-0,68)$ \\
\hline
\end{tabular}

${ }_{1}^{1}$ Intraklassekorrelasjonskoeffisientestimater med $95 \%$ konfidensintervall, basert på gjennomsnittlig vurdering $(\mathrm{n}=4)$, absolutt enighet (konsistens for kvalitetsvurdering), tosidig blandet effekt-modell.

\section{RETT TIL HELSEHJELP}

Primær- og sekundærvurderingene ga samlet sett $63 \%$ «rett til helsehjelp», mens 37 \% fikk «ikke rett til helsehjelp».

Tabell 3 viser at $18 \%$ av henvisningene ble vurdert likt av alle sentrene. Tre av fire sentre vurderte likt for $45 \%$ av henvisningene. For $38 \%$ av henvisningene ga to sentre rett til helsehjelp, mens to avviste rett til helsehjelp. Andel enighet mellom alle sentrene var $69 \%$, hvilket er lavere enn grensen for «akseptabel enighet» på $75 \%$.

\section{Tabell 3}

Vurdering av henvisninger $(\mathrm{N}=40)$ mht. rett til helsehjelp. Enighet mellom primær- og sekundærvurderinger samt mellom sekundærvurderingene, $\mathrm{n}(\%)$.

\begin{tabular}{|lrrrrr|}
\hline & $\begin{array}{c}\text { Fire sentre } \\
\text { enige }\end{array}$ & $\begin{array}{c}\text { Tre } \\
\text { sentre } \\
\text { enige }\end{array}$ & $\begin{array}{c}\text { To sentre Ingen sentre } \\
\text { enige }\end{array}$ & $\begin{array}{c}\text { Andel } \\
\text { enige } \\
\text { enighet } \\
(\%)\end{array}$ \\
\hline $\begin{array}{l}\text { Primær- og } \\
\text { sekundærvurdering (fire } \\
\text { sentre) }\end{array}$ & $7(18)$ & $18(45)$ & $15(38)$ & $\begin{array}{l}\text { Ikke } \\
\text { aktuelt }\end{array}$ & 69 \\
\hline $\begin{array}{l}\text { Sekundærvurdering (tre } \\
\text { sentre) }\end{array}$ & $\begin{array}{r}\text { lkke } \\
\text { aktuelt }\end{array}$ & $10(25)$ & $26(65)$ & $4(10)$ & 68 \\
\hline
\end{tabular}

I sekundærvurderingene vurderte alle tre sentrene likt i $25 \%$ av tilfellene, mens to sentre vurderte likt i $65 \%$ av tilfellene. I $10 \%$ av tilfellene vurderte sentrene ulikt. Grad av samsvar var $68 \%$. Supplerende informasjon fra pasientjournal ble benyttet i $68 \%$ av primærvurderingene, mens sekundærvurderingene ble foretatt på grunnlag av 
henvisningen alene. Tabell 4 viser enighet mellom hvert primærvurderende team og de respektive sekundærvurderingene.

\section{Tabell 4}

Henvisninger gitt rett til helsehjelp per senter, $\mathrm{n}(\%)$. Enighet mellom primær- og sekundærvurderinger. Henvisninger gitt vurderingen «mer informasjon nødvending» er holdt utenfor. HUS = Haukeland universitetssjukehus, OUS = Oslo universitetssykehus, STO $=$ St. Olavs hospital, UNN = Universitetssykehuset Nord-Norge.

\begin{tabular}{|c|c|c|c|c|c|c|}
\hline \multicolumn{7}{|c|}{ Gitt rett til helsehjelp } \\
\hline \multirow[t]{2}{*}{ Senter } & \multirow[t]{2}{*}{ Primærvurdering } & \multicolumn{4}{|c|}{ Sekundærvurdering } & \multirow{2}{*}{$\begin{array}{c}\text { Andel enighet } \\
(\%)\end{array}$} \\
\hline & & HUS & UNN & OUS & STO & \\
\hline $\operatorname{HUS}(n=10)$ & $6(60)$ & - & $8(80)$ & $4(40)$ & $9(90)$ & 78 \\
\hline UNN $(n=10)$ & $6(60)$ & $7(78)^{1}$ & - & $3(30)$ & $2(33)^{4}$ & 60 \\
\hline OUS $(n=10)$ & $7(70)$ & $8(80)$ & $4(67)^{2}$ & - & $5(100)^{5}$ & 65 \\
\hline STO $(n=10)$ & $6(60)$ & $4(40)$ & $5(63)^{3}$ & $5(50)$ & - & 70 \\
\hline \multicolumn{7}{|l|}{ UNN (n=9) } \\
\hline \multicolumn{7}{|l|}{${ }^{2} \mathrm{OUS}(\mathrm{n}=6)$} \\
\hline \multicolumn{7}{|l|}{${ }^{3} \mathrm{STO}(\mathrm{n}=8)$} \\
\hline \multicolumn{7}{|l|}{${ }^{4} \mathrm{UNN}(\mathrm{n}=6)$} \\
\hline${ }^{5} \mathrm{OUS}(\mathrm{n}=5)$ & & & & & & \\
\hline
\end{tabular}

\section{Diskusjon}

Formålet med denne studien var å undersøke i hvilken grad de fire regionale smertesentrene i Norge har sammenfallende vurderinger av kvaliteten på mottatte henvisninger og konklusjoner om pasientenes rett til nødvending helsehjelp. Vurdering av innholdet i henvisningene viste at 7 av 16 informasjonskategorier i stor grad ikke var tilstrekkelig beskrevet, og inntaksteamene vurderte kvaliteten på nær halvparten av henvisningene som «ikke god». Disse funnene samsvarer med tidligere studier $(7,8,10)$ og bekrefter inntrykket av at henvisninger i mange tilfeller ikke holder god nok kvalitet og ofte mangler vesentlig informasjon for å foreta adekvat rettighetsvurdering $\mathrm{i}$ spesialisthelsetjenesten.

Mangelfull informasjon var en viktig årsak til at en stor andel av henvisningene ble karakterisert som «ikke god». Langvarig smerte er en sammensatt tilstand, og det kreves bred kompetanse for å beskrive sykdommens kompleksitet. Lav kvalitet på henvisninger kan være et uttrykk for at henviser har behov for kompetanseheving. Fastleger er sentrale henvisere, men i vår studie kom henvisninger både fra fastleger og spesialisthelsetjenesten, uten at vi var i stand til å skille mellom dem. Listen over informasjon som er anbefalt å ta med, er lang (3), men sannsynligvis er ikke all anbefalt informasjon relevant for alle pasienter. Adekvat informasjon må formidles i henvisingen, men en mest mulig korrekt utvelgelse av informasjon er en utfordring ikke bare for henviser, men også for smerteklinikkene. Vi fant at det var moderat til lav enighet mellom inntaksteamene i vurdering av kvalitet. Det betyr at samme henvisning ble oppfattet forskjellig i de ulike teamene, noe som kan være et uttrykk for forskjell i kompetanse og erfaring mellom inntaksteamene. Dette kan forårsake ulik vekting av informasjonen i henvisningene, og signaliserer behov for harmonisering av vurdering av innholdet.

Samlet sett var andel enighet mellom inntaksteamene om hvem som skulle få rett til 
helsehjelp, lavere enn det som regnes som akseptabelt. Primærvurderingene og sekundærvurderingene ga $63 \%$ rett til helsehjelp, men andel enighet var $69 \%$. Inntaksteamene hadde ingen fasit å gå ut fra, og vurderingene ble gjort på grunnlag av informasjon i henvisningene, eventuell tilgang til supplerende informasjon $\mathrm{i}$ pasientjournalen, veiledende retningslinjer og inntaksteamets erfaringer. Det kan dermed diskuteres hva som er tilstrekkelig grad av enighet. Våre resultater samsvarer med funn fra tidligere studier. Ikezawa og medarbeidere (2010) undersøkte om klinikere som arbeidet ved samme rehabiliteringssenter, ga like tilbake-til-jobbanbefalinger. For pasienter med entydig patologi fant de stor enighet (>94\%) om hvilken informasjon som var viktig i vurderingen av pasienters utskrivelsesstatus, men lav enighet der årsaken til smerte og uførhet var kompleks (56\%) (22). Også i en norsk studie fra inntaksteam ved 16 distriktspsykiatriske sentre fant man lav enighet i rettighetsvurderingene for 20 utvalgte henvisninger (13). Ovennevnte funn reflekterer utfordringene som oppstår når pasientens sykdomsbilde ikke kan vurderes ut fra et klassisk medisinsk og patologi-orientert perspektiv, noe som er karakteristisk for pasientpopulasjonen i vår studie.

Våre resultater tyder på at hvorvidt en smertepasient får rett til helsehjelp, er avhengig av hvilket senter som vurderer henvisningen. Forskjellene mellom vurderingene kan reflektere ulik kompetanse på sentrene, men også forskjeller i behandlingstilbud innenfor og utenfor sykehuset. Så lenge kompetanse og behandlingstilbud ikke blir eksplisitt formidlet, kan skjulte og uønskede ulikheter mellom helseregionene oppstå. Resultatene kan også indikere at prioriteringsveilederen for smertetilstander (4) bør gjennomgås på nytt. I tillegg kan man vurdere om den bør tilpasses denne sammensatte pasientgruppen.

Det er anerkjent at systemet med henvisninger bør struktureres (23, 24). Standardisering av henvisningsskjemaer og retningslinjer samt involvering av klinikere i undervisning om henvisningsprosessen har vist å gi forbedring (9). Rokstad og medarbeidere (2013) fant at kvaliteten på spesialisthenvisningene ble høynet etter innføring av et retningsgivende informasjonssystem. Systemet ble benyttet av 93 (intervensjonsgruppen) av i alt 210 fastleger. Kvaliteten på henvisningene ble signifikant bedre, og tidsbruken gikk ned (25). Våre funn understreker behovet for en fastere struktur som kan veilede henviser i hvilken informasjon som er nødvendig.

Svakheter med vår studie er det relativt lave antall henvisninger som ble vurdert (40 i alt), og at kartleggingsskjemaet for henvisningene ikke var validert. Primærvurderende senter hadde tilgang til ytterligere bakgrunnsinformasjon gjennom pasientjournalen, hvilket svekket sammenligningen med sekundærvurderingene. Inntaksteamene måtte innenfor vanlige tidsrammer sekundærvurdere 30 henvisningskopier utover de vanlige henvisningene. Dette kan ha ført til mindre grundig gjennomgang og påvirket rettighetsvurderingen. Studien har en styrke i at den er virkelighetsnær, da alle vurderingene ble foretatt innenfor vanlige kliniske rammer.

\section{Konklusjon}

Vår studie viser at en stor andel av pasienthenvisningene til fire store tverrfaglige smertesentre har lav kvalitet og gir utilstrekkelig informasjon. Sentrene ga rett til helsehjelp i $63 \%$ av henvisningene, men det var under akseptabel grad av enighet mellom sentrene om hvilke pasienter som var kvalifisert til helsehjelp. Funnene taler for et system med mer strukturerte henvisninger, harmonisering av vurderinger og en tydeligere prioriteringsveileder som kan bidra til et likeverdig pasienttilbud i de ulike regionene.

\section{HOVEDBUDSKAP}

Nær 50 \% av henvisningene til tverrfaglige smertesentre ga utilstrekkelig informasjon for vurdering av rett til helsehjelp 
For kun én av fem henvisninger var det absolutt samsvar mellom inntaksteamene i rettighetsvurderingen

\section{LITTERATUR:}

1. Landmark T, Romundstad P, Dale O et al. Estimating the prevalence of chronic pain: validation of recall against longitudinal reporting (the HUNT pain study). Pain 2012; 153: 1368-73.

[PubMed][CrossRef]

2. Breivik H, Collett B, Ventafridda V et al. Survey of chronic pain in Europe: prevalence, impact on daily life, and treatment. Eur J Pain 20o6; 10: 287-333. [PubMed][CrossRef]

3. Organisering og drift av tverrfaglige smerteklinikker. Veileder IS-219o. Oslo: Helsedirektoratet, 2015. https://helsedirektoratet.no/Lists/Publikasjoner/Attachments/873/Veileder-Organisering-og-drift-av-tv errfaglige-smerteklinikker-IS-219o.pdf(15.2.2019).

4. Helsedirektoratet. Prioriteringsveileder-smertetilstander.

https://helsedirektoratet.no/retningslinjer/smertetilstander (15.2.2019).

5. FOR-2000-12-01-1208. Forskrift om prioritering av helsetjenester, rett til nødvendig helsehjelp fra spesialisthelsetjenesten, rett til behandling i utlandet og om klagenemnd (prioriteringsforskriften). https://lovdata.no/dokument/SF/forskrift/2000-12-01-1208 (15.2.2019).

6. LOV-1999-07-02-63. Lov om pasient- og brukerrettigheter (pasient- og brukerrettighetsloven). https://lovdata.no/dokument/NL/lov/1999-07-02-63 (15.2.2019).

7. Lønning KJ, Kongshavn T, Husebye E. Kvaliteten på henvisninger fra fastleger til medisinsk poliklinikk. Tidsskr Nor Legeforen 2009; 129:1868-9. [PubMed][CrossRef]

8. Gulati S, Jakola AS, Solheim O et al. Assessment of referrals to a multidisciplinary outpatient clinic for patients with back pain. J Manual Manip Ther 2012; 20: 23-7. [PubMed][CrossRef]

9. Akbari A, Mayhew A, Al-Alawi MA et al. Interventions to improve outpatient referrals from primary care to secondary care. Cochrane Database Syst Rev 2008; 4: CDoo5471. [PubMed]

10. Grupe P, Grinsted P, Møldrup M et al. Kvalitetsforbedringer af henvisninger fra praksissektoren. Ugeskr Laeger 2006; 168:1434-8. [PubMed]

11. Skipnes DP. Prosedyrer for pasientprioritering ved Smerteavdelingen. Masteroppgave. Troms $\emptyset$ : Profesjonsstudie i medisin, Norges arktiske universitet, 2015.

12. Thorsen $O$, Hartveit M, Baerheim A. The consultants' role in the referring process with general practitioners: partners or adjudicators? a qualitative study. BMC Fam Pract 2013; 14: 153. [PubMed][CrossRef]

13. Holman PA, Ruud T, Grepperud S. Horizontal equity and mental health care: a study of priority ratings by clinicians and teams at outpatient clinics. BMC Health Serv Res 2012; 12: 162. [PubMed][CrossRef]

14. Oppdragsdokument 2015. Helse Midt-Norge RHF. Oslo: Helse og omsorgsdepartementet, 2015. https://www.regjeringen.no/globalassets/departementene/hod/opp2hmn.pdf(15.2.2019).

15. Prop. 1 S (2014-2015). https://www.regjeringen.no/no/dokumenter/Prop-1-S-20142015/id2005458/ (15.2.2019).

16. Prop. 1 S (2015-2016). https://www.regjeringen.no/no/dokumenter/prop.-1-s-sd-20152016/id2456147/ (15.2.2019).

17. Norsk senter for forskningsdata. Meldeskjema for behandling av personopplysninger. https://nsd.no/personvernombud/meld_prosjekt/meldeskjema (15.2.2019).

18. McHugh ML. Interrater reliability: the kappa statistic. Biochem Med (Zagreb) 2012; 22: 276-82. [PubMed][CrossRef]

19. Koo TK, Li MY. A guideline of selecting and reporting intraclass correlation coefficients for reliability research. J Chiropr Med 2016; 15: 155-63. [PubMed][CrossRef]

20. Graham M, Milanowski A, Miller J. Measuring and promoting inter-rater agreement of teacher and principal performance ratings. Center for Educator Compensation Reform, 2012. 
https://files.eric.ed.gov/fulltext/ED532068.pdf(15.2.2019).

21. Montgomery AA, Graham A, Evans PH et al. Inter-rater agreement in the scoring of abstracts submitted to a primary care research conference. BMC Health Serv Res 2002; 2: 8. [PubMed][CrossRef]

22. Ikezawa Y, Battié MC, Beach J et al. Do clinicians working within the same context make consistent return-to-work recommendations? J Occup Rehabil 2010; 20:367-77. [PubMed][CrossRef]

23. Medisinsk-faglig innhold i henvisninger: «den gode henvisning». KITH rapport nr. 22/o3. Trondheim: Kompetansesenter for IT i helsevesenet, 2003.

24. Thorsen O, Hartveit M, Kristoffersen JE et al. Vi trenger en ny type henvisninger. Tidsskr Nor Legeforen 2017; 137: 607. [PubMed][CrossRef]

25. Rokstad IS, Rokstad KS, Holmen S et al. Electronic optional guidelines as a tool to improve the process of referring patients to specialized care: an intervention study. Scand J Prim Health Care 2013; 31: 166-71. [PubMed][CrossRef]

Publisert: 23. mai 2019. Tidsskr Nor Legeforen. DOI: 10.4045/tidsskr.18.0396

Mottatt 4.5.2018, første revisjon innsendt 3.12.2018, godkjent 15.2.2019.

(C) Tidsskrift for Den norske legeforening 2020. Lastet ned fra tidsskriftet.no 